University of Nebraska - Lincoln

DigitalCommons@University of Nebraska - Lincoln

April 1991

\title{
Synchrotron-radiation-induced deposition of boron and boron carbide films from boranes and carboranes: Decaborane
}

\author{
F. Keith Perkins \\ University of Wisconsin, Madison
}

R.A. Rosenberg

Synchrotron Radiation Center, University of Wisconsin, Stoughton

Sunwoo Lee

Syracuse University

Peter A. Dowben

University of Nebraska-Lincoln, pdowben@unl.edu

Follow this and additional works at: https://digitalcommons.unl.edu/physicsdowben

Part of the Physics Commons

Perkins, F. Keith; Rosenberg, R.A.; Lee, Sunwoo; and Dowben, Peter A., "Synchrotron-radiation-induced deposition of boron and boron carbide films from boranes and carboranes: Decaborane" (1991). Peter Dowben Publications. 103.

https://digitalcommons.unl.edu/physicsdowben/103

This Article is brought to you for free and open access by the Research Papers in Physics and Astronomy at DigitalCommons@University of Nebraska - Lincoln. It has been accepted for inclusion in Peter Dowben Publications by an authorized administrator of DigitalCommons@University of Nebraska - Lincoln. 


\title{
Synchrotron-radiation-induced deposition of boron and boron carbide films from boranes and carboranes: Decaborane
}

\author{
F. Keith Perkins ${ }^{\text {a) }}$ \\ Materials Science Program, University of Wisconsin, Madison, Wisconsin 53706 \\ R. A. Rosenberg \\ Synchrotron Radiation Center, University of Wisconsin, 3731 Schneider Dr., Stoughton, Wisconsin 53589 \\ Sunwoo Lee and P. A. Dowben ${ }^{\text {a) }}$ \\ Department of Physics, Syracuse University, Syracuse, New York 13244-1130
}

(Received 25 October 1990; accepted for publication 19 December 1990)

\begin{abstract}
Boron has been deposited successfully on $\mathrm{Si}(111)$ from the synchrotron-radiation-induced decomposition of decaborane (14), i.e., $\mathrm{B}_{10} \mathrm{H}_{14}$. The rate of deposition is limited by the adsorption rate of decaborane (14) on the surface. In addition there is some indication that there is an activation barrier to dissociative adsorption. The synchrotron-radiationinduced growth rate of boron thin films from decaborane (14) is linear with coverage for a large range of thickness, suggesting a constant sticking coefficient for decaborane adsorption at room temperature.
\end{abstract}

\section{INTRODUCTION}

The modification of the electronic structure of silicon surfaces through the adsorption and chemical vapor deposition of boron is well established. ${ }^{1-8}$ Recently, ${ }^{6-12}$ decaborane (14) has been shown to be a suitable boron source for the chemical vapor deposition of boron films and an alternative to diborane (6) $\left(\mathrm{B}_{2} \mathrm{H}_{6}\right),{ }^{13-15} \mathrm{BCl}_{3},{ }^{3,16,17} \mathrm{BF}_{3},{ }^{18,19}$ and trimethylboron $\left[\mathrm{B}\left(\mathrm{CH}_{3}\right)_{3}\right]$ (Ref. 1) in the selective area deposition of boron.

Boron and boron carbides (as well as many other boron-containing thin films) have great potential in the modification of surfaces because of the desirable semiconductor properties, ${ }^{1-8,20-27}$ hardness, ${ }^{28-30}$ and radiation absorption characteristics. ${ }^{31,32}$ We have explored the synchrotron-radiation-induced deposition of boron and boron carbide thin films from single-source compounds because of the great potential of $x$ rays for very highresolution selective area processing. ${ }^{33,34}$ Boranes and carboranes are potential single-source compounds for the deposition of boron and boron carbides containing no impurities other than hydrogen and thus producing films whose stoichiometry is insensitive to the precise decomposition pathway. The carboranes can be modified to control the film composition of carbon and boron. In this paper, boron deposition from the synchrotron-radiation-induced decomposition of decarborane will be discussed, and in a companion paper we will present evidence of boron carbide deposition from a carborane (diethyl-carborane).

\section{EXPERIMENT}

Decaborane (14), $\mathrm{B}_{10} \mathrm{H}_{14}$, is an air-stable white crystalline solid with a vapor pressure of several Torr at room temperature. ${ }^{35}$ The vapor pressure can be raised readily by heating the decaborane, since the molecule decomposes only above $170{ }^{\circ} \mathrm{C}^{36}$ The vapor pressure of decaborane (14) is given by ${ }^{37}$

$$
\begin{aligned}
\log \left[F_{\text {vap }}(\mathrm{mm})\right]= & -3218.5 / T+1.75 \log (T) \\
& -0.005372 T+7.4106,
\end{aligned}
$$

or about 19 Torr at $100^{\circ} \mathrm{C}$. The decaborane was sublimed to separate the material from cellite (a stabilizer) and other impurities.

The deposition experiments were carried out in a white light beam line previously described ${ }^{34}$ at the Synchrotron Radiation Center in Stoughton, Wisconsin. Briefly, the broad band synchrotron radiation, with $545 \mathrm{eV}$ critical energy, was focused on the sample with a fluence of $5 \times 10^{13}$ photons $/ \mathrm{s}^{-1} \mathrm{~mA}^{-1} \mathrm{~mm}^{-2}$. Typical beam currents ranged from 60 to $140 \mathrm{~mA}$. The synchrotron radiation was focused by a grazing incidence reflection from a Au-coated ellipsoidal mirror at an angle of $86.8^{\circ}$ off incidence. The deposition chamber was equipped with a singlepass CMA, a manipulator, and a residual gas analyzer. The general configuration of the vacuum system is schematically outlined in Fig. 1. We also have performed photoemission measurements of decaborane exposed to $\mathrm{Si}(111)$ ( $7 \times 7$ reconstructed surface) at $100 \mathrm{~K}$, using a cylindrical mirror analyzer and synchrotron light dispersed by a toroidal grating monochromator as described elsewhere. ${ }^{38}$

The samples were of polished $p$-type $\mathrm{Si}(111)$ doped to about $1 \times 10^{15} \mathrm{~cm}^{-3}$. The samples were prepared in situ by 500-eV $\mathrm{Ar}^{+}$-ion bombardment and flash annealing to $1000^{\circ} \mathrm{C}$ until the surface was determined to be clean by white light Auger electron spectroscopy (AES) as described elsewhere. ${ }^{34}$ This has been found by other work$\mathrm{ers}^{39}$ to give a $7 \times 7$ reconstruction of the $\mathrm{Si}(111)$. None of the data presented in this work was taken from surfaces sputtered more than twice. The surface of silicon (111)

a) Address correspondence to either of these authors. 


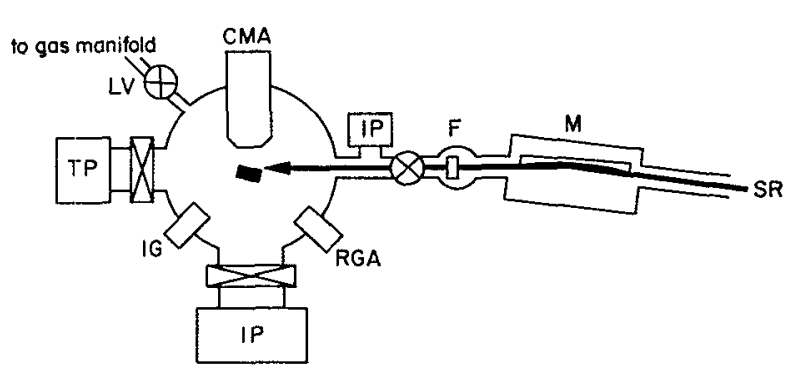

FIG. 1. A schematic representation of the white light beam line. The synchrotron radiation (SR) is focused by a mirror into the experimental chamber, separated from the beam line by differential pumping (IP). A filter (F) can be inserted into the synchrotron radiation to block or filter the light. The main chamber is pumped by an ion pump (IP) and turbomolecilar pump (TP). The system is equipped with a quadrupole mass spectrometer (RGA) for photostimulated desorption studies and residual gas analysis, a cylindrical mirror analyzer (CMA) for Auger electron spectroscopy (AES), an ion gun (IG) for ion bombardment of the surface, and a leak valve (LV) for controlling gas flow into the vacuum system.

and the thin-film growth was characterized in situ by photostimulated Auger electron spectroscopy under uhv conditions. In this way, we could reduce contamination of the film that occurs with hot filament electron sources because of the substantial reactivity of the boron films, ${ }^{9}$ as well as carry out ongoing process monitoring.

A.ll pressures and sticking coefficients reported in this work are uncorrected for the ionization gauge cross section of decaborane.

\section{RESULTS AND DISCUSSION}

A. Si(111) surface was exposed to $\mathrm{B}_{10} \mathrm{H}_{14}$ in the presence of synchrotron-radiation (SR) white light. In the absence of this high-energy radiation, decaborane (14) is observed to decompose only slowly and to only a very small coverage as seen in Fig. 2. As discussed later, this coverage can be roughly estimated to be much less than $1 \mathrm{~A}$ and may be related to the defect density of the surface (though this is not confirmed). Adsorbed species readily desorb in vacuo $\left(<10^{-9}\right.$ Torr at a substrate temperature between $300-475 \mathrm{~K}$ ) leaving the surface free of boron as determined by subsequent Auger electron spectroscopy. ${ }^{40}$

From photoemission spectra taken from the surface following exposure to decaborane (14) at $100 \mathrm{~K}$, as seen in Fig. 3, we conclude that the initial adsorption of decaborane is largely molecular. The photoemission spectra exhibit features that can be assigned to the molecular orbitals and resemble the photoemission features reported for gaseous decaborane (14)..$^{4 l-44}$ The differences between the gaseous photoemission spectra ${ }^{43,44}$ and our adsorbed species can be attributed to spectral broadening of the photoemission features common with many molecular adsorption systems. ${ }^{45}$ These photoemission results, seen in Fig. 3, and the facile desorption of adsorbed boron species, support molecular or associative adsorption as the initial stage in the boron film growth. Avouris et al. have reported the adsorption of molecular decaborane at room temperature on reconstructed $\mathrm{Si}(111)$ with the molecule adsorbing

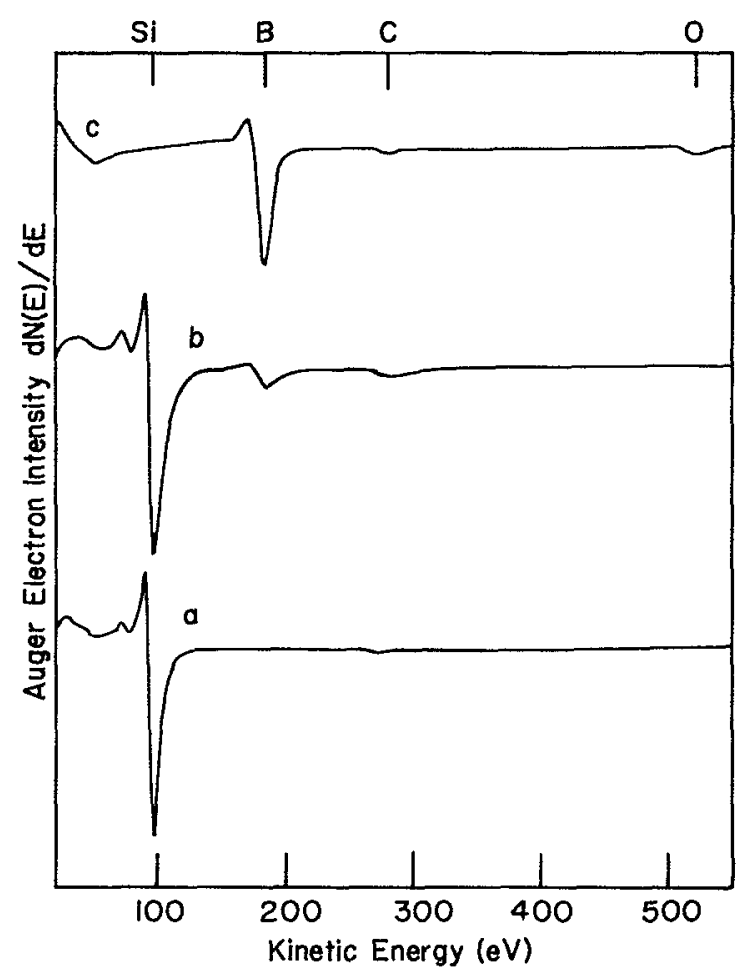

FIG. 2. Auger electron spectra of (a) clean silicon (111), (b) following 75-L decaborane exposure in the absence of light, and (c) following $38 \mathrm{~L}$ exposure in the presence of synchrotron radiation. Spectrum (b) is equivalent to less than $1 / 10$ of a monolayer of boron using estimates based upon mean free path arguments and the intensity of the silicon Auger electron spectroscopy signal.

preferentially on defect sites and on center atoms of the $7 \times 7$ surface. ${ }^{6,7}$ These results also support a preliminary molecular adsorption mechanism.

Somewhat in contradiction to our results, Avouris et al., ${ }^{6-8}$ observed that decaborane does not desorb in vacuo at room temperature or above. Rather, they report that the hydrogen desorbs above $800 \mathrm{~K}$ leaving sufficient boron for a $\sqrt{3} \times \sqrt{3} R 30^{\circ}$ reconstruction induced by the boron overlayer. The reconstruction is completed by $1300 \mathrm{~K}$. Their results suggest that this molecular bond is quite strong and survives to a temperature where thermal decomposition occurs. From our results, the coverages for which this is true must be quite small.

Upon exposure to SR white light, the decaborane (14) decomposes resulting in an increasing boron surface coverage. From white light Auger electron spectra, the increase in the boron coverage is readily apparent (Fig. 4) for decaborane exposure to $\mathrm{Si}(111)$ in the presence of SR. The SR deposited boron does not readily desorb in vacuo and is therefore not as volatile as the decaborane (14). Without the incident radiation, increases in the boron coverage are not observed with decaborane (14) exposures to $\mathrm{Si}(111)$ at substrate temperatures in the vicinity of $300 \mathrm{~K}$ (Fig. 2). From these results we can conclude that radiation is essential in assisting the decomposition process of decaborane. The photoassisted deposition of boron from decaborane can be used to selectively deposit boron with excel- 


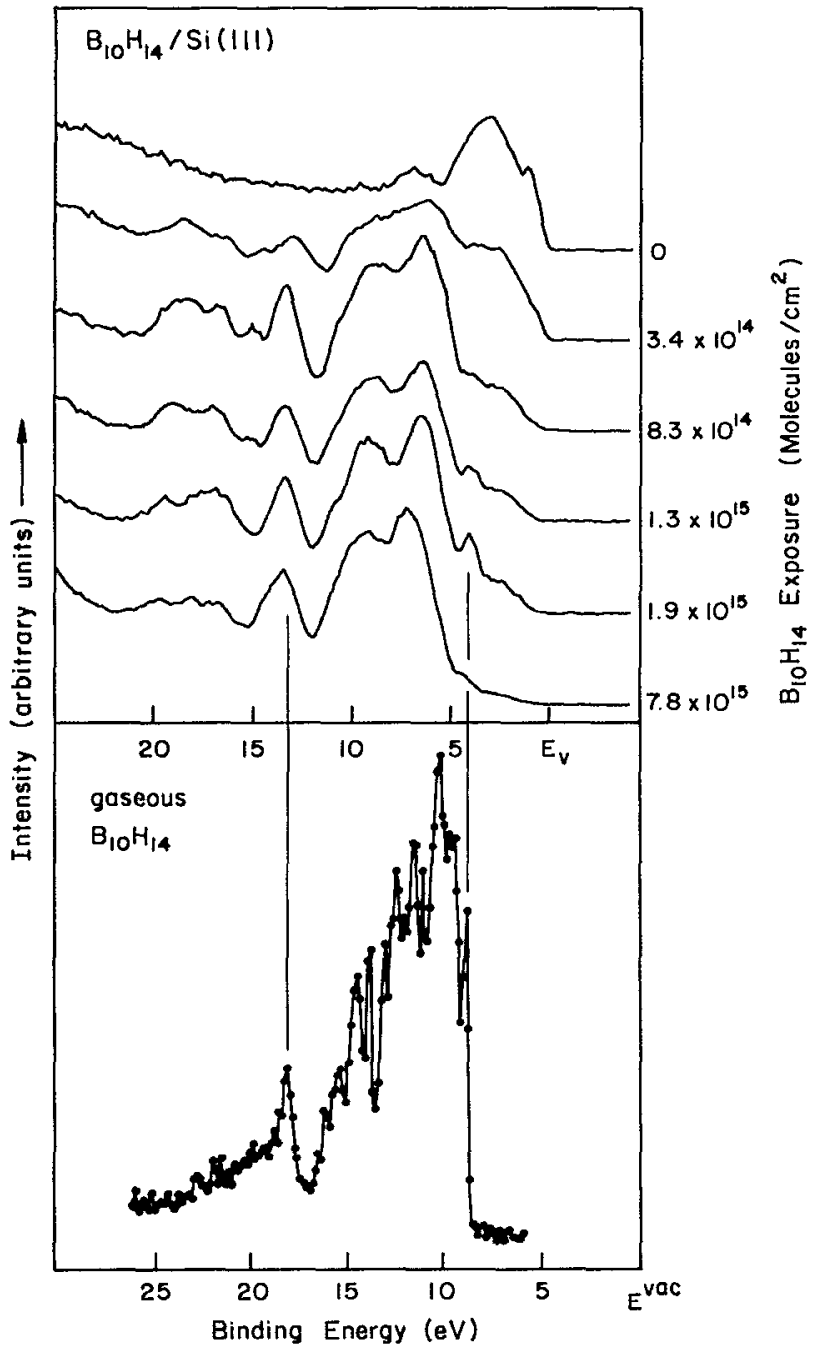

FIG. 3. Photoemission spectra of gaseous decaborane (bottom) and $\mathrm{Si}(111)$ at $100 \mathrm{~K}$ following exposure to decaborane (14) (top). All the photoemission spectra were taken with a photon energy of $55 \mathrm{eV}$.

lent spatial resolution (micrometer or less) using closecontact masks. ${ }^{9,40}$ Since the selective area deposition using either uv (Ref. 6) or soft $x$-ray radiation ${ }^{40}$ does not result in boron deposition where the light is not incident upon the surface at room temperature, we have concluded that the photoassisted deposition of boron from decaborane is a surface process that requires adsorption of decaborane (14), and some process for dissociating the decaborane.

Since the broad band synchrotron radiation contains a range of photon energies, filters were employed to ascertain whether soft $\mathrm{x}$ rays or light in the vacuum ultraviolet is more effective in assisting in the decomposition of decaborane to produce boron thin films. With a sapphire window, blocking the radiation at energies greater than $8 \mathrm{eV}$, no substantial increases in the surface boron coverages were observed upon exposing room-temperature $\mathrm{Si}(111)$ to $90 \mathrm{~L}$ (langmuirs) of $\mathrm{B}_{10} \mathrm{H}_{14}$ with $2 \mathrm{~A}$ h of synchrotron radiation. This is less boron found on the surface of $\mathrm{Si}(111)$ after $1 \mathrm{~L}$ decaborane (14) exposure accompanied by the full spectrum of SR white light to assist in decomposition.

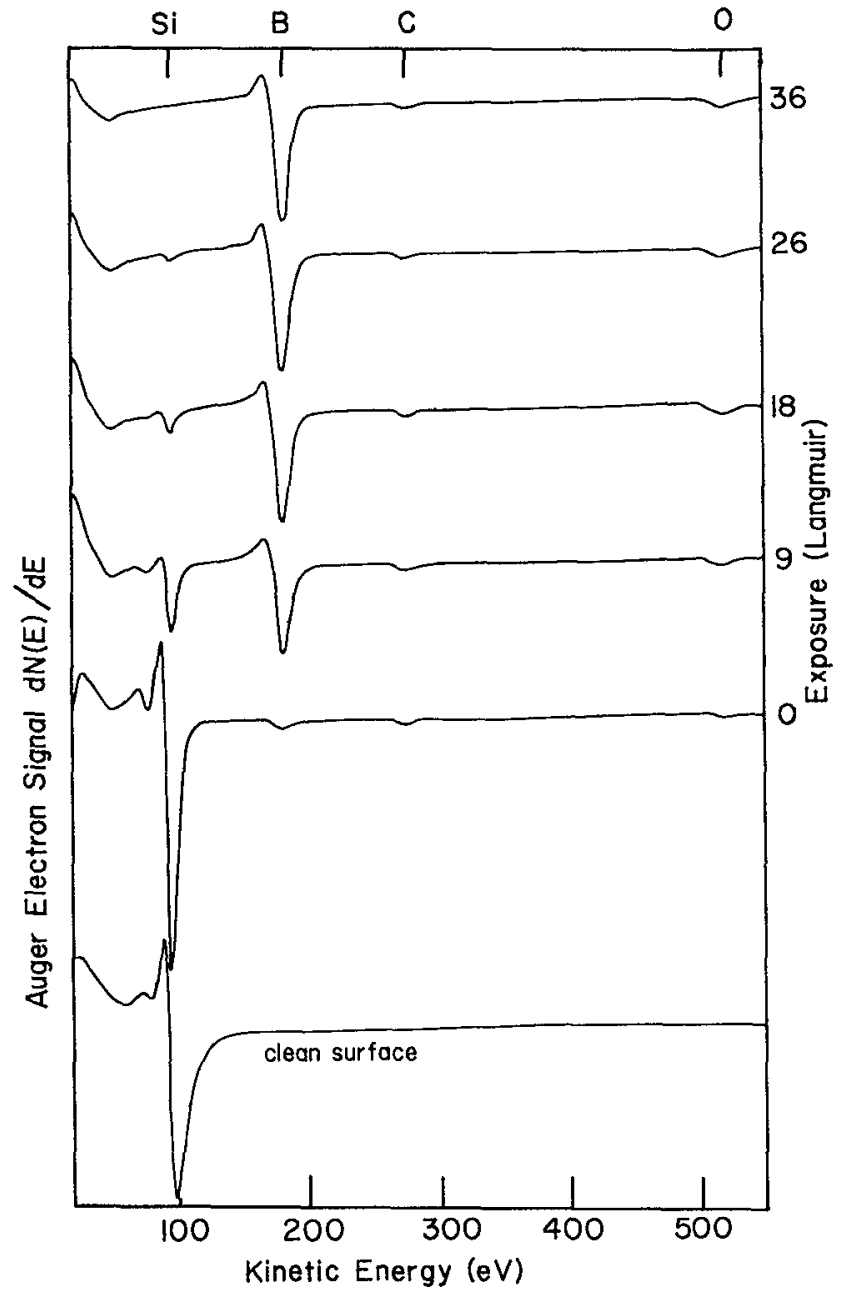

FIG. 4. A sequence of white light Auger electron spectra taken from $\mathrm{Si}(111)$ at room temperature following exposure to decaborane (14) at $8 \times 10^{-9}$ Torr in the presence of synchrotron radiation. The time of SR exposure is indicated.

Boron thin films can be grown from decaborone (14) using ultraviolet light $t^{6}$ but laser light sources are required for a flux sufficient to obtain an appreciable deposition rate and the decomposition of decaborane remains a surface (not gaseous) process. Soft $\mathrm{x}$ rays generate a large number of secondary electrons with kinetic energies between 5 and 10 $\mathrm{eV} .{ }^{46}$ This number of secondary electrons can be far larger than that generated by light at lower photon energies because of the multiple excitation and inelastic loss processes possible at higher photon energies and the greater escape depth for electrons of higher kinetic energies. The adsorption cross section of boron-containing species over the range of energy of the emitted light from the Wisconsin synchrotron (Aladdin) soft $\mathrm{x}$-ray region (neglecting the uv) is likely to be rather weak, ${ }^{47}$ whereas the low-energy electron impact cross section is relatively large. Therefore, the direct photoabsorption of a soft $\mathrm{x}$-ray photon is far less likely to induce decomposition of decaborane than a lowenergy electron collisions. Assuming that there is a surface lifetime of $1 \mathrm{~s}$ (which is probably unrealistically large by several orders of magnitude) of the molecular precursor 

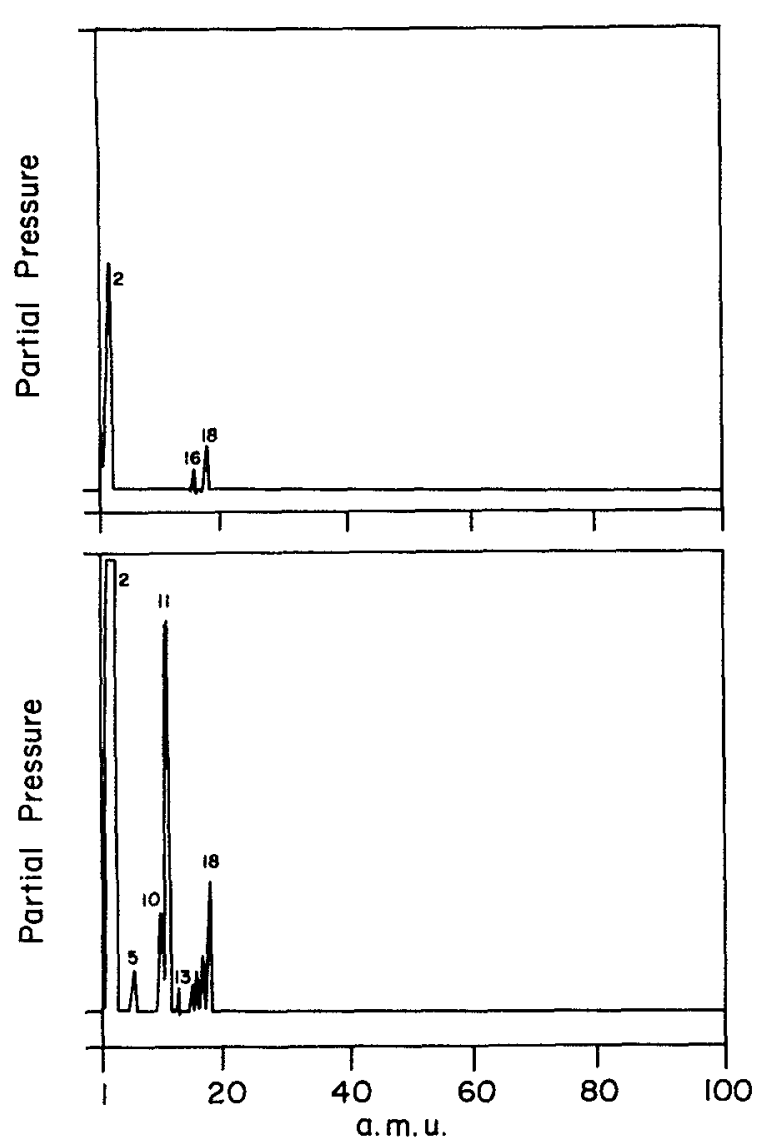

FIG. 5. Mass spectrum during synchrotron-radiation-stimulated deposition of boron on $\mathrm{Si}(111)$ from decaborane (bottom). A reference residual gas mass spectrum is also shown.

species at room temperature, the "average" quantum efficiency would have to be at least 0.025 per photon, which would be surprising, and several orders of magnitude (even with our unrealistic assumption) too large for direct $x$-ray absorption.

Decaborane, from our results, requires a substantial flux of $\mathrm{x}$ rays and a large number of decaborane molecules to obtain any sort of detectable fragmentation in the gas phase and requires a quantum efficiency greater than 1 to account for the results of Fig. 5. Both these conditions are not met in our deposition experiment. The large rate of dissociative decaborane adsorption induced by synchrotron radiation in the soft $x$-ray region as well as the apparent surface mediation of the decomposition process suggests it is the secondary electrons generated in the substrate that are the primary decomposition mechanism. Hot electrons have also been implicated as the major mechanism leading to photoassisted decomposition of organometallic compounds on surfaces such as adsorbed metal hexacarbonyls, ${ }^{34,48-51}$ as well as the dissociation of halogenated methanes. ${ }^{38,52}$

The deposition of boron from the synchrotron-induced dissociative adsorption of $\mathrm{B}_{10} \mathrm{H}_{14}$ is largely native boron as determined by NEXAFS, which exhibited spectral features very similar to native boron and dissimilar from condensed decaboborane (14). ${ }^{40}$ In addition, postdeposition atomic absorption spectroscopy does not indicate any large amount of hydrogen $(<6 \%)$. Synchrotron radiation white light decomposition of decaborane results in substantial hydrogen production and may induce photostimulated desorption of some native boron from the surface in vacuo as indicated by the increase in the mass spectrometer mass 10- and 11-a.u. signals (in the correct isotopic ratio) and hydrogen signal as seen in Fig. 5. Larger fragments that would result from the dissociation of $\mathrm{B}_{10} \mathrm{H}_{14}$ in the gas phase are not seen in photostimulated desorption. Our results strongly suggest that hydrogen is eliminated from the growing boron film in the SR-induced decomposition of decaborane.

Studies of boron films grown from the plasma-assisted decomposition of decaborane (14) (Refs. 9 and 10) have shown that these films also contain little hydrogen $(<6 \%)$ by atomic absorption spectroscopy. Plasma-assisted decomposition is also largely a result of electron impact with electrons of kinetic energies between $10-100 \mathrm{eV} .^{53-55}$ Since both plasma-assisted and synchrotron-radiation-assisted deposition of boron from the decomposition of decaborane involve electron-induced fragmentation processes, it is not surprising that both methods result in formation of films with similar compositions.

Changes in the synchrotron-radiation (SR) white light flux as a result of changes in the stored synchrotron current have little effect upon the SR-induced decaborane decomposition for stored beam currents in the synchrotron between 45 and $110 \mathrm{~mA}$. Only with very small beam currents $(<20 \mathrm{~mA}$ ) is the radiation flux sufficiently reduced to result in an appreciable reduction in the rate of dissociative adsorption of $\mathrm{B}_{10} \mathrm{H}_{14}$. This result can be reconciled with secondary-electron-induced dissociation of $\mathrm{B}_{10} \mathrm{H}_{14}$ if the secondary electron flux from the substrate, generated by the synchrotron radiation, is large.

Since the secondary electron flux that initiates the principle pathway for decomposition of decaborane (14) is large, then the synchrotron-radiation-induced decomposition of decaborane is limited by the surface coverage and lifetime of the weakly adsorbed molecular $\mathrm{B}_{10} \mathrm{H}_{14}$ surface species. Such a model is supported by the $\mathbf{B}_{10} \mathbf{H}_{14}$ pressure and $\mathrm{Si}(111)$ substrate temperature sticking coefficient dependence of the SR-induced dissociative adsorption. As can be seen in Fig. 6, the SR-induced boron film growth rate increases proportionally with the $\mathrm{B}_{10} \mathrm{H}_{14}$ pressure over a wide range of pressures in a manner that can be explained by the increase in the molecular impingement rate with pressure. The relationship between decaborane pressure and the film growth rate is linear with pressure over a wide range of decaborane pressures. The initial sticking coefficient is therefore independent of pressure, for decaborane pressures below $1 \times 10^{-7}$ Torr.

From the decay of silicon substrate signal plotted in Fig. 7 , one can make a rough estimate of the thickness of the growing boron film. This has been done in Fig. 8. The thickness is based upon assuming an exponential attenuation of Auger electrons from silicon through the growing boron film according to 


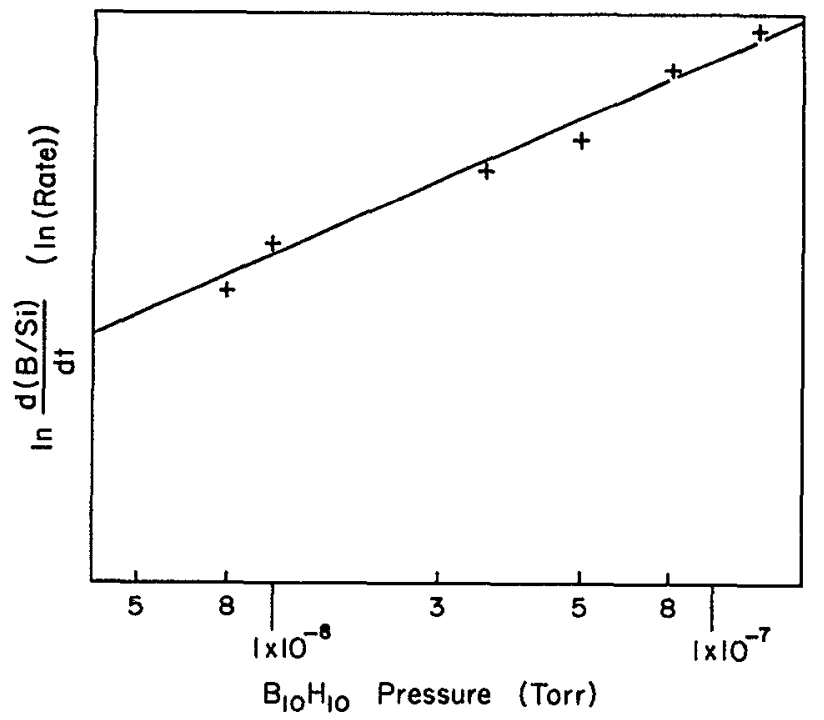

FIG. 6. The initial boron film growth rate on $\mathrm{Si}(111)$ at room temperature from decaborane, as a function of pressure. The stored synchrotron beam currents ranged from 50 to $110 \mathrm{~mA}$.

$$
D=-k \ln \left(I / I_{0}\right)
$$

where $k$ is the mean free path for a $92-\mathrm{eV}$ electron (the silicon Auger electron line) times the cosine of the emission angle into the cylindrical mirror analyzer $\left(48^{\circ}\right)$. The

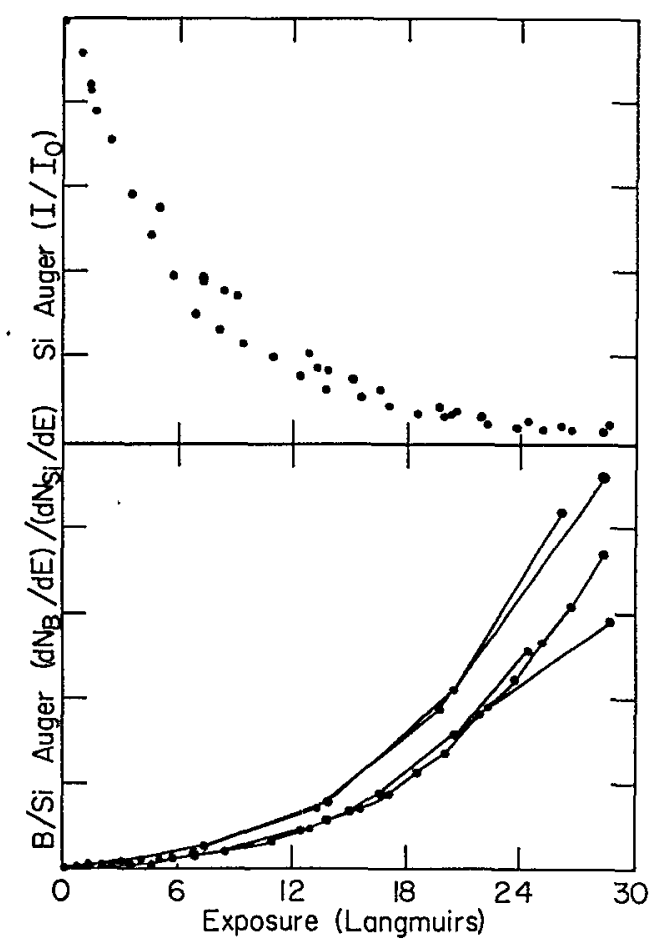

FIG. 7. The synchrotron-light-induced dissociative boron deposition on $\mathrm{Si}(111)$ at room temperature as a function of exposure. Data is included for a range of pressures from $5 \times 10^{-8}$ to $1 \times 10^{-7}$ Torr. Both the decay of the substrate Auger electron signal at $92 \mathrm{eV}$ (top), and the boron-tosilicon Auger electron signal intensities (bottom) are shown.

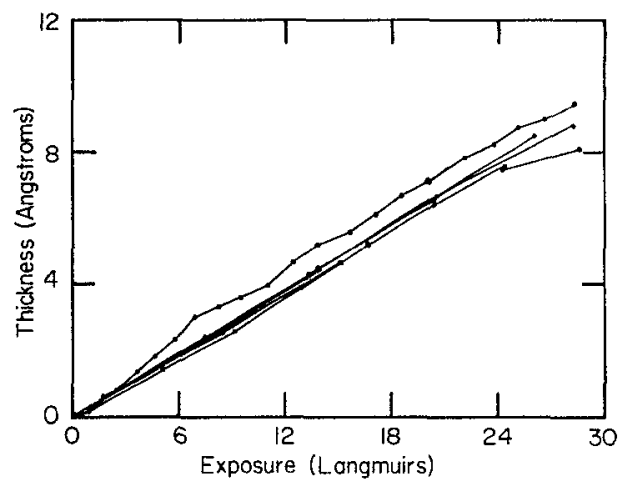

FIG. 8. The boron film thickness measured from the attentuation of the silicon substrate Auger electron signal as a function of decaborane exposure during synchrotron-radiation-induced deposition of boron on $\mathrm{Si}(111)$ at room temperature. The different lines indicate different data sets. The data has been reduced from Fig. 7 .

mean free path of $3.6 \mathrm{~A}$ was estimated based upon the room-temperature equilibrium density of boron and from the universal curve of Seah and Dench ${ }^{56}$ and Lindau and Spicer. ${ }^{57}$ The results show that the growth rate is constant and therefore is independent of coverage for several monolayers for depositions at room temperature and below. Such a result is consistent with a secondary-electronactivated process, and existence of an extrinsic precursor state.

Probably $\mathrm{B}_{10} \mathrm{H}_{14}$ (or possibly other volatile borane clusters, though diborane and pentaborane are unlikely), as we have determined from the results above, weakly chemisorbs or physisorbs upon the $\operatorname{Si}(111)$ surface. The heat of sublimation of decaborane (14) has been determined to be $19.4 \mathrm{kcal} / \mathrm{mol}^{36}$ The synchrotron-radiationinduced dissociative sticking coefficient as a function of the $\mathrm{Si}(111)$ substrate temperature, for a fixed $\mathrm{B}_{10} \mathrm{H}_{14}$ pressure, is shown in Fig. 9, for temperatures well above room tem-

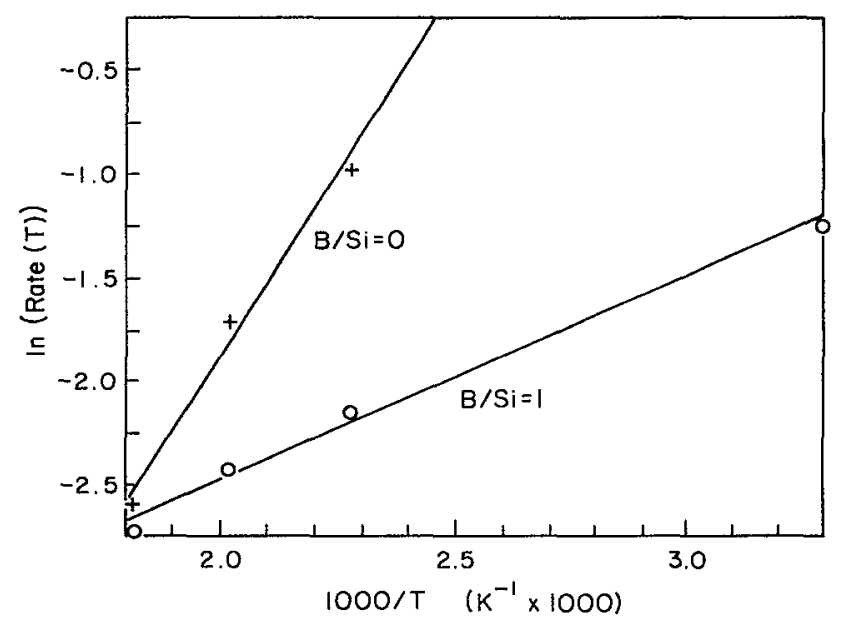

FIG. 9. The logarithm of the synchrotron-radiation-induced dissociative adsorption rate vs $1 /$ temperature for decaborane on $\mathrm{Si}(111)$, on clean $\mathrm{Si}(111)(\mathrm{B} / \mathrm{Si}=0)$, and on approximately one monolayer of deposited boron $(\mathrm{B} / \mathrm{Si}=1)$. 
perature. It is clear that for temperatures well above room temperature, the deposition rate is no longer independent of coverage and desorption dominates the thin-film growth process. The temperature-dependent rate for the SRinduced dissociative adsorption of $\mathrm{B}_{10} \mathrm{H}_{14}$ can be modeled by an Arrhenius expression where the initial temperaturedependent rate goes as $R=R_{0} \exp \left(305 \mathrm{meV} / K_{B} T\right)$ and changes to $R=R_{0} \exp \left(85 \mathrm{meV} / K_{B} T\right)$ upon completion of an adsorbed monolayer of boron for temperatures well above room temperature. The positive sign for the energy term in the partition function indicates that desorption dominates the SR-induced deposition from decomposition of decaborane. The effective activation barrier to desorption of $0.305 \mathrm{eV} /$ molecule for the initial dissociative adsorption process and $0.085 \mathrm{eV} /$ molecule for coverages greater than a monolayer of boron is far less than the heat of sublimation of $0.84 \mathrm{eV} .{ }^{36}$ SR-induced photo- and electrostimulated desorption could effectively reduce the activation barrier to desorption by a substantial amount, but this would be rather temperature insensitive. While SRinduced desorption effects cannot be excluded, an activation barrier to dissociation would, effectively, reduce our measured activation barrier to dissociation. By treating the molecularly adsorbed decaborane (14) as a precursor state, then the simplest of models is that the molecule either desorbs or dissociates. The rate of dissociative adsorption that we have measured $R(T)$ will vary with temperature $T$ according to

$$
R(T)=A \exp \left(-E_{A} / K_{B} T\right)-B \exp \left(E_{d} / K_{B} T\right),
$$

where $E_{A}$ is the effective activation barrier to synchrotronradiation-induced dissociation, and $E_{d}$ is the activation barrier for desorption in vacuo. In this simple model it is clear that, since the slope of the lines in Fig. 9 are positive, the effective barrier to dissociation of decaborane is of a comparable size or greater than the heat of desorption. It is difficult, with the present data, to explain unequivocally these results in the absence of detailed studies of the decomposition of $\mathrm{B}_{10} \mathrm{H}_{14}$ surface species on $\mathrm{Si}(111)$ and boron and in the absence of knowledge about the heats of desorption for molecular decaborane. Boron surfaces appear to have a vastly different activation barrier to $\mathbf{B}_{10} \mathrm{H}_{14}$ dissociation than silicon. Complications as a result of the changing density of states and the production of secondary electrons may also be a factor.

There is strong evidence to support the existence of a precursor state to dissociative adsorption. We have clearly identified that molecular adsorption of decaborane does occur at low temperature. From the adsorption data we can estimate the synchrotron-radiation-induced film growth rate as a function of coverage as seen in Fig. 8. From Fig. 8 it is clear that the film growth rate is constant over a very wide range of coverage for substrate temperatures near room temperature. This implies that the synchrotron-radiation-induced dissociative adsorption process has a constant "sticking" coefficient over this coverage range. Such a constant sticking coefficient is incompatible with langmuir adsorption isotherms but is consistent with the existence of a precursor state. ${ }^{58}$ The strong activation barrier to dissociation, the observed surface selectivity, and the low sticking coefficient are all also consistent with the existence of a precursor state. The precursor state(s) to dissociative adsorption (assisted by SR) may comprise intermediate species other than decaborane (14) given the size of this complex. ${ }^{59}$

\section{CONCLUSION}

We have demonstrated that we can deposit boron with synchrotron radiation from $\mathrm{B}_{10} \mathrm{H}_{14}$. The activation barrier for dissociative decarborane adsorption appears to be of a comparable size to the heat of desorption (if not greater still). The results suggest that clean $\mathrm{Si}(111)$ will stabilize the large borane cluster against dissociation, though the reasons for this require further investigation. Our results strongly suggest that molecular adsorption of decaborane is the precursor to dissociative adsorption consistent with recent STM studies. ${ }^{6.7}$ but the details of the molecular interaction with the surface require further study if the decomposition pathways are to be identified.

Our results are consistent with the postulate that decaborane (14) does not readily dissociate on $\mathrm{Si}(111)$ at room temperature and below and is therefore a suitable candidate for selective area deposition of boron. This selective area processing is possible because, from our results, it is clear that the boron deposition is localized largely to the areas illuminated with radiation. ${ }^{40}$ Because molecular adsorption is only a precursor to dissociative adsorption and radiation is essential for decomposition, resolution of the incident radiation may be the only limitation to highly selective deposition.

A molecular borane of some form adsorbs at room temperature, though with a very small surface coverage and short surface residence lifetime. This precursor state may be "frozen" in by cooling the surface to $100 \mathrm{~K}$ [in which case the precursor state is decaborane (14)].

\section{ACKNOWLEDGMENTS}

We would like to thank Derrick Mancini, Kim Tan, S. Frigo, Jin Ming Chen, Shikha Varma, and Marshall Onellion for their assistance in making this work possible. These measurements were carried out at the Synchrotron Radiation Center, in Stoughton, Wisconsin, which is supported by the National Science Foundation. This work was funded through Rome Air Development Center (RADC) under Contract No. F30602-89-C-0113, and by the Wisconsin Alumni Research Foundation.

${ }^{1}$ T. F. Deutsch, J. C. C. Fan, G. W. Turner, R. L. Chapman, D. J. Ehrlich, and R. M. Osgood, Jr., Appl. Phys. Lett. 38, 144 (1981)

${ }^{2}$ H. Hirayama, T. Tasumi, and N. Aizaki, Surf. Sci. 193, L47 (1988).

${ }^{3}$ F. Foulon, A. Slaoi, E. Fquarassy, R. Stuck, C. Fuchs, and P. Siffert, Appl. Surf, Sci. 36, 384 (1989).

${ }^{4}$ A. B. McLean, L. J. Terminello, and F. J. Himpsel, Phys. Rev. B 41, 7694 (1990).

${ }^{5}$ P. Bedrossian, D. M. Chen, K. Mortensen, and J. A. Golovchenko, Nature 342, 258 (1989).

${ }^{6} \mathrm{Ph}$. Avoiris, I. -W. Lyo, F. Bozso, and E. Kaxiras, J. Vac. Sci. Technol. A 8, 3405 (1990).

${ }^{7} \mathrm{Ph}$. Avouris, J. Phys. Chem. 94, 2246 (1990). 
${ }^{8}$ I. -W. Lyo, E. Kaxiras, and Ph. Avouris, Phys. Rev. Lett. 63, 1261 (1989).

${ }^{9}$ Y. G. Kim, P. A. Dowben, J. T. Spencer, and G. O. Ramseyer, J. Vac. Sci. Technol. A 7, 2796 (1989).

${ }^{10}$ Z. Zhang, Y. -G. Kim, P. A. Dowben, and J. T. Spencer, Mater. Res. Soc. Symp. Proc. 131, Chemical Perspectives of Microelectronic Materials, Edited by Gross, Jasinski, and Yates (1989) 401.

"J. T. Spencer, P. A. Dowben, and Y. -G. Kim, U. S. Patent No. 4, 957, 773 (18 September 1990).

${ }^{12}$ J. Mazurowski, S. Baral-Tosh, G. Ramseyer, J. T. Spencer, Y. -G. Kim, and P. A. Dowben, Mat. Res. Soc. Symp. Proc. 190 (1990).

${ }^{13}$ S. Komatsu and Y. Moriyoshi, J. Appl. Phys. 64, 1878 (1988).

${ }^{14}$ C. Braganza, S. Veprek, and P. Groner, J. Nucl. Mater. 88-86, 1133 (1979).

${ }^{15}$ H. O. Pierson and A. W. Mullendore, Thin Solid Films 83, 87 (1981).

${ }^{16}$ R. Nipoti, M. Bianconi, R. Fabbri, M. Servidor, S. Nicolletti, and R. Canteri, Appl. Surf. Sci. 43, 321 (1989).

${ }^{17}$ D. K. Kuehl, R. Ranti, and S. F. Galasso, U. S. Patent No. 3,811,930 (XX month 1974).

${ }^{18}$ F. Foulon, A. Sloaui, and P. Siffert, Appl. Surf. Sci. 43, 333 (1989).

${ }^{19}$ P. G. Carey and T. W. Sigmon, Appl. Surf. Sci. 43, 325 (1989).

${ }^{20}$ J. Mazurowski, Y. -G. Kim, G. O. Ramseyer, and P. A. Dowben (unpublished).

${ }^{21}$ P. Bedrossian, R. D. Meade, K. Mortensen, D. M. Chen, J. A. Golovchenko, and D. Vanderbilt, Phys. Rev. Lett. 63, 1257 (1989).

${ }^{22}$ D. Tomanek, R. M. Wentzcovitch, S. G. Louie, and M. L. Cohen, Phys. Rev. B 37, 3134 (1988).

${ }^{23}$ W. Baronian, Mater. Res. Bull. 7, 119 (1972).

${ }^{24}$ A. J. Nadolny, Phys. Status Solidi B 65, 801 (1974).

${ }^{25}$ A. J. Nadolny, J. Less-Common Met. 67, 125 (1979).

${ }^{20} \mathrm{G}$. V. Panteleeva and V. V. Morozkin, J. Less-Common Met. 67, 205 (1979).

${ }^{27}$ A. Szadkowski, J. Less-Common Met. 67, 551 (1979).

${ }^{28}$ A. R. Badzian, Mater. Res. Bull, 16, 1385 (1981).

${ }^{29}$ A. R. Badzian, Appl. Phys. Lett. 53, 2495 (1988).

${ }^{30}$ A. R. Badzian, in Advances in $X$-ray Analysis, edited by C. S. Barrett, J. V. Gilfrich, R. Jenkins, J. C. Russ, J. W. Richardsen, and P. K. Predecki (Plenum, New York, 1988), Vol. 31, p. 113.

${ }^{31}$ V. C. George, A. K. Dua, and R. P. Agarwala, Thin Solid Films 164, 135 (1988).

${ }^{32}$ H. O. Pierson and A. W. Mullendore, Thin Solid Films 63, 257 (1979).

${ }^{33}$ P. A. Dowben, J. T. Spencer, and G. T. Stauf, Mater. Sci. Eng. B 2, 297 (1989).

${ }^{34}$ D. C. Mancini, S. Varma, J. K. Simons, R. A. Rosenberg, and P. A.
Dowben, J. Vac. Sci. Technol. B 8, 1804 (1990).

${ }^{35}$ D. F. Shriver and M. A. Drezdzen, The Manipulation of Air-Sensitive Compounds, 2nd ed. (Wiley, New York, 1986).

${ }^{36}$ Callery Chemical Company, Technical Bulletin No. CM-070, 1971.

${ }^{37}$ P. T. Hurd and M. M. Stafford, U. S. Patent No. 2,558,559 (June 26, 1954); P. T. Hurd and M. M. Stafford, U.S. Patent No. 2,558,561 (June 26, 1954).

${ }^{38}$ C. R. Wren and R. A. Rosenberg, Surf. Sci. 218, L483 (1989).

${ }^{39}$ R. G. Musket, W. Mclean, C. A. Colmenares, D. M. Makonieky, and W. J. Siekhaus, Appl. Surf. Sci. 10, 143 (1982).

${ }^{40}$ R. A. Rosenberg, F. K. Perkins, D. C. Mancini, G. Harp, B. Tonner, S. Lee, and P. A. Dowben, Appl. Phys. Lett. 58, 607 (1991).

${ }^{41}$ L. A. Laws, R. M. Stevens, and W. N. Lipscomb, J. Am. Chem. 44, 4467 (1972).

${ }^{42}$ M. F. Guest and I. H. Hillier, J. C. S. Faraday II, 2004 (1974).

${ }^{43}$ D. R. Lloyd, N. Lynaugh, P. J. Roberts, and M. F. Guest, J. C. S. Faraday II, 1382 (1975).

${ }^{44}$ J. - M. Chen, K. -H. Tan, M. Bancroft, and R. A. Rosenberg (unpublished).

${ }^{45}$ W. D. Grobman and E. E. Koch, in Photoemission in Solids II, edited by L. Ley and M. Cardona (Springer, Berlin, 1979).

${ }^{46}$ A. D. Baker and C. R. Brundle, in Electron Spectroscopy: Theory, Techniques and Applications, edited by C. R. Brundle and A. D. Baker (Academic, New York, 1977), Vol. 1.

${ }^{47}$ J. J. Yeh and I. Lindau, At. Data Nucl. Data Tables 32, 1 (1985).

${ }^{48}$ Y. C. Ying and W. Ho, Phys. Rev. Lett. 65, 741 (1990).

${ }^{49}$ J. S. Foord and R. B. Jackman, Chem. Phys. Lett. 112, 190 (1984).

${ }^{50}$ R. B. Jackman and J. S. Foord, Extended Abstracts, Laser, Chemical Processing of Semiconductor Devices, Mat. Res. Soc. Symp. Proc., 67 (1984).

${ }^{51}$ T. A. Germer and W. Ho, J. Chem. Phys. 89, 562 (1988).

${ }^{52}$ P. A. Dowben and M. Grunze, Ber. Bunsenges. Phys. Chem. 85, 728 (1981); C. R. Wen and R. A. Rosenberg, Surf. Sci. 218, L483 (1989).

${ }^{53}$ R. Reif, J. Vac. Sci. Technol. A 2, 429 (1984).

${ }^{54}$ M. R. Wertheimer, J. Vac. Sci. Technol. A 3, 2643 (1985).

${ }^{55}$ M. J. Rand, J. Vac. Sci. Technol. 16, 420 (1979).

${ }^{56}$ M. P. Seah and W. E. Dench, Surf. Interf. Anal. 1, 2 (1979).

${ }^{57}$ I. Lindau and W. E. Spicer, J. Electron Spectrosc. Relat. Phenom. 3, 409 (1974).

${ }^{58}$ M. W. Roberts and C. S. McKee, Chemistry of the Gas-Metal Interface (Clarendon, Oxford, 1978).

${ }^{59}$ L. J. Whitman, S. A. Joyce, Y. A. Yarmoff, F. R. McFeely, and L. J. Terminello, Surf. Sci. 232, 297 (1990); P. Gupta, P. A. Coon, B. G. Koehler, and S. M. George, J. Chem. Phys. 93, 2827 (1990). 